\title{
Isoflurane Preconditioning Ameliorates Renal Ischemia-Reperfusion Injury through Antiinflammatory and Antiapoptotic Actions in Rats
}

\author{
Yaoxian Liang, ${ }^{a, \#}$ Zhengqian Li, ${ }^{b, \#} \mathrm{Na} \mathrm{Mo},{ }^{c}$ Min Li ${ }^{b}$ Zhen Zhuang, ${ }^{a}$ Jun Wang, ${ }^{b}$ Yue Wang, ${ }^{* a}$ and \\ Xiangyang Guo*,b \\ ${ }^{a}$ Department of Nephrology, Peking University Third Hospital; ${ }^{b}$ Department of Anesthesiology, Peking University \\ Third Hospital; Beijing 100191, China: and ${ }^{C}$ Cancer Institute and Hospital, Chinese Academy of Medical Sciences; \\ Beijing 100021, China. \\ Received March 6, 2014; accepted July 22, 2014; advance publication released online August 2, 2014
}

\begin{abstract}
Renal ischemia-reperfusion (I/R) injury is a major cause of acute kidney injury via inflammation and cell apoptosis. Volatile anesthetics have been shown to exert organ-protective effects against kidney damage in vivo and in vitro. In the present study, we investigated the effects of isoflurane, a commonly used volatile anesthetic, on renal I/R injury and the underlying mechanisms. Rats subjected to renal I/R displayed higher serum creatinine and blood urea nitrogen levels than sham rats as well as severe histopathological damage. Renal $I / R$ also resulted in a nuclear factor- $\kappa$ B (NF- $\kappa$ B)-mediated inflammatory response and dysfunction of the p53-Bax-caspase-3 apoptotic pathway. Rats preconditioned with $1.5 \%$ isoflurane for $2 \mathrm{~h}$ had better renal function and less tubular apoptosis $24 \mathrm{~h}$ after $\mathbf{I} / \mathrm{R}$ injury than control rats. Pretreatment with isoflurane suppressed renal NF- $\kappa$ B activation, leading to a reduction in proinflammatory molecules (high-mobility group box 1 , interleukin- $1 \beta$, and tumor necrosis factor- $\alpha$ ) both in the kidneys and circulation. In addition, rats subjected to isoflurane preconditioning had a higher Bcl-2/Bax ratio and less cleaved caspase-3. Our findings suggest that preconditioning with a clinically relevant concentration of isoflurane attenuates renal $I / R$ injury, based at least in part on its ability to modulate renal inflammation and apoptosis.
\end{abstract}

Key words acute kidney injury; ischemia-reperfusion; volatile anesthetic; inflammation; apoptosis

Renal ischemic-reperfusion (I/R) injury is a major cause of acute kidney injury (AKI), which occurs in many clinical settings including shock, renal transplantation, and renal artery angioplasty. ${ }^{1)}$ Renal I/R injury always implies a poor prognosis and no effective therapy is currently available. Although the underlying mechanisms for renal $I / R$ injury have been extensively studied, the pathophysiologic process involving inflammation and cell apoptosis and its relationship to subsequent renal injury remain to be fully elucidated.

Nuclear factor $-\kappa \mathrm{B}(\mathrm{NF}-\kappa \mathrm{B})$ is one of the most critical transcription factors involved in many inflammatory conditions, including renal I/R injury. Activation of $N F-\kappa B$ is a critical step in the systemic and renal inflammatory response, which leads to the release of proinflammatory cytokines including high-mobility group box 1 (HMGB1), ${ }^{2)}$ interleukin- $1 \beta$ $(\mathrm{IL}-1 \beta),{ }^{3)}$ and tumor necrosis factor- $\alpha(\mathrm{TNF}-\alpha){ }^{4)}$ It has also been observed that the p53-Bax-caspase-3 apoptotic pathway is involved in renal I/R injury. ${ }^{4,5)}$ P53 can induce the downregulation of anti-apoptotic $\mathrm{Bcl}-2$ and the upregulation of pro-apoptotic Bax. A decrease in the Bcl-2/Bax ratio triggers cytochrome $c$ release from mitochondria, which results in the activation of caspase- 3 and a chain reaction leading to apoptosis. ${ }^{67)}$ Therefore, inhibiting the coexisting processes of inflammation and apoptosis provides a potential approach to the prevention and treatment of renal I/R injury.

Isoflurane is a volatile anesthetic commonly used in clinical surgical settings. Previous studies have indicated that, in addition to its anesthetic effects, isoflurane protects tissue from I/R injury in several organs including the heart, ${ }^{8)}$ liver, ${ }^{9)}$ and brain. ${ }^{10)}$ Moreover, isoflurane has been shown to have a pharmacological preconditioning effect against $\mathrm{I} / \mathrm{R}$ injury in the

The authors declare no conflict of interest.

\# These authors contributed equally to this work. kidney by upregulating hypoxia inducible factor-1 $\alpha$ (HIF-1 $\alpha$ ) and blunting the activation of c-Jun $\mathrm{N}$ terminal kinase (JNK) and extracellular signal-regulated kinase (ERK). ${ }^{11,12)}$

Nevertheless, it is not known whether isoflurane preconditioning could protect against renal $\mathrm{I} / \mathrm{R}$ injury by modulating the NF- $\kappa$ B-mediated inflammatory response and/or the p53Bax-caspase-3 apoptotic pathway. In the present study, we aimed to better understand whether isoflurane preconditioning protects against renal $\mathrm{I} / \mathrm{R}$ injury in an in vivo rat model. We also investigated whether any renoprotection could be attributed to reducing inflammation and/or regulating apoptosis.

\section{MATERIALS AND METHODS}

Animals and Experimental Groups Male Sprague Dawley rats (Department of Laboratory Animal Science, Peking University Health Science Centre, Beijing, China) weighing 300-350 g were used in this study. Animals were bred and maintained under standardized housing conditions with food and water ad libitum. All experiments were conducted in accordance with protocols approved by the Peking University Biomedical Ethics Committee Experimental Animal Ethics Branch (Beijing, China). Twenty-four rats were randomly divided into three groups with eight animals in each group using the random table method. The groups were defined as sham-operated control (Sham), renal I/R (I/R), and isoflurane preconditioning before renal $\mathrm{I} / \mathrm{R}$ (ISO $+\mathrm{I} / \mathrm{R}$ ).

Isoflurane Preconditioning Isoflurane preconditioning was performed according to our previous studies. ${ }^{13,14)}$ In brief, rats were placed in a temperature-controlled, transparent anesthetic chamber with inflow and outflow hoses. Isoflurane (Baxter Healthcare, Deerfield, IL, U.S.A.) was delivered in $100 \%$ oxygen at $2 \mathrm{~L} / \mathrm{min}$ using agent specific vaporizers. Standard soda lime was placed at the bottom of the con- 
tainer to clear the carbon dioxide. Gas composition including isoflurane, oxygen, and carbon dioxide within the anesthetic chamber was continuously analyzed with a gas monitor (Datex-Ohmeda, Louisville, CO, U.S.A.) by sampling gas at the outflow hose. Rats in the ISO $+\mathrm{I} / \mathrm{R}$ group received $1.5 \%$ isoflurane for $2 \mathrm{~h}$ followed by $30 \mathrm{~min}$ of wash-out before I/R. Rats in the sham and I/R groups received only $100 \%$ oxygen for $2 \mathrm{~h}$. This dosing protocol of isoflurane has been shown to not only have no cardiorespiratory compromise, but also effectively ameliorate renal I/R injury in mice. ${ }^{11)}$ All rats breathed spontaneously in the chamber.

Renal I/R Injury The acute renal I/R injury model was created as described previously. ${ }^{15)}$ Briefly, rats were anesthetized with an intraperitoneal injection of $30 \mathrm{mg} / \mathrm{kg}$ pentobarbital sodium. After intradermal injections of $0.25 \%$ bupivacaine, a midline laparotomy was performed. Then the right kidney was removed, and the left kidney pedicle was shut by an artery clamp for $30 \mathrm{~min}$. After $30 \mathrm{~min}$ of left renal ischemia, occlusion clips were removed, and the incision was closed in two layers. The same procedure was performed in the sham group without the unilateral clamping process.

Assessment of Renal Function Serum creatinine (Scr) and blood urea nitrogen (BUN) levels were measured using an automatic biochemical analyzer (Olympus AU 5400, Tokyo, Japan) by hospital research services.

Histopathological Evaluation Formalin-fixed renal tissue was dehydrated, embedded in paraffin, and sliced into $5-\mu \mathrm{m}$-thick sections, which were stained with hematoxylin and eosin by standard methods. Histopathological scoring was performed in a blinded manner. Renal injury was defined as cellular swelling of the tubules, brush border loss, tubular dilatation, tubule cast formation, tubular necrosis, or inflammatory cell infiltration in the inner cortex and outer medullary regions. A scoring scale of 0 to 4 was used: no injury (0), less than $25 \%$ (1), less than $50 \%$ (2), less than $75 \%$ (3), or more than $75 \%$ (4). For each section, at least 20 fields were examined under $\times 400$ magnification and the average score was determined as the comprehensive evaluation for each animal. ${ }^{16)}$

Renal and Systemic Inflammation Assessment After $24 \mathrm{~h}$ reperfusion, renal and systemic inflammation was determined by measurement of serum HMGB1, TNF- $\alpha$, and IL- $1 \beta$ concentrations. Blood samples were collected transcardially after thoracotomy, and serum was separated by centrifugation at $3000 \times \boldsymbol{g}$ for $10 \mathrm{~min}$ at $4^{\circ} \mathrm{C}$. The homogenates from the renal cortices were centrifuged at $10000 \times \boldsymbol{g}$ for $10 \mathrm{~min}$ at $4^{\circ} \mathrm{C}$. All samples were then stored at $-80^{\circ} \mathrm{C}$ until analysis was performed. Levels of HMGB1, TNF- $\alpha$, and IL- $1 \beta$ were measured by ELISA following the manufacturer's instructions (R\&D Systems, Minneapolis, MN, U.S.A.). Each experimental condition was tested in three different wells and measured in duplicate. Total protein concentration in kidney homogenates was determined with a BCA protein assay kit (Applygen Technologies Inc., Beijing, China) and renal cytokine levels were expressed as $\mathrm{ng} / \mathrm{g}$ or $\mu \mathrm{g} / \mathrm{g}$ protein.

Determination of Renal Apoptosis Renal apoptosis was detected by a terminal deoxynucleotidyl transferase-mediated deoxyuridine triphosphate (dUTP) nick-end labeling (TUNEL) assay with an in situ Cell Death Detection Kit (Roche Applied Science, Mannheim, Germany) following the manufacturer's instructions. Briefly, formalin-fixed sections $5 \mu \mathrm{m}$ thick were dewaxed and rehydrated. Then, they were permeabilized with
$10 \mu \mathrm{g} / \mathrm{mL}$ proteinase $\mathrm{K}$ in $10 \mathrm{~mm}$ Tris-HCL buffer, $\mathrm{pH} 7.6$, for $30 \mathrm{~min}$ at room temperature. The slides were then incubated with TUNEL reaction mixture in a humidified chamber for $60 \mathrm{~min}$ at $37^{\circ} \mathrm{C}$ in the dark. Finally, sections were rinsed three times in PBS and nuclei were mounted with 4',6-diamidino2-phenylindole (DAPI) at a concentration of $300 \mathrm{~nm}$. Apoptosis was quantified by calculating the percentage of TUNEL-positive nuclei out of total nuclei in an average of 20 high-power fields for each section in a blinded manner.

Western Blot Analysis Western blot analysis was performed to determine the expression of phosphorylated IKK $\alpha / \beta$ $(\mathrm{p}-\mathrm{IKK} \alpha / \beta)$, phosphorylated $\mathrm{I} \kappa \mathrm{B} \alpha(\mathrm{p}-\mathrm{I} \kappa \mathrm{B} \alpha), \mathrm{I} \kappa \mathrm{B} \alpha, \mathrm{Bax}, \mathrm{Bcl}-2$, and cleaved caspase- 3 as previously described. ${ }^{13)}$ In brief, tissues were homogenized in cold RIPA buffer, and the quantity of protein in the supernatants was determined using a BCA protein assay kit (Applygen Technologies Inc., Beijing, China). Sixty micrograms protein per lane was loaded on $10 \%$ sodium dodecyl sulfate-polyacrylamide gel electrophoresis (SDS-PAGE). After transfer to a nitrocellulose membrane, the proteins were probed with the following primary antibodies: mouse anti-p-I $\kappa \mathrm{B} \alpha$ antibodies $(1: 1000, \mathrm{CST}$, Danvers, MA, U.S.A.); rabbit anti-I $\kappa \mathrm{B} \alpha$ and anti-pIKK antibodies $(1: 1000$, CST); and rabbit anti-Bax, anti-Bcl-2, and anti-caspase-3 antibodies (1:1000; Santa Cruz Biotechnology, Santa Cruz, CA, U.S.A.). Fluorescent secondary antibodies (1: 10000; LI-COR Biosciences, Lincoln, NE, U.S.A.) were used to detect the binding of primary antibodies. Proteins were visualized by scanning the membrane on an Odyssey Infrared Imaging System (LI-COR Biosciences).

Quantitative Real-Time Reverse Transcriptase Polymerase Chain Reaction (PCR) Total RNA was extracted from the kidney tissues with Eastep Universal RNA Extraction Kit (Promega, Madison, WI, U.S.A.) and the concentration was assessed using a Nanodrop spectrophotometer (Thermo Scientific, Waltham, MA, U.S.A.). Then, $2 \mu \mathrm{g}$ of total RNA was reverse transcribed with M-MLV Reverse Transcriptase. Real-time PCR was performed using SYBR green Master Mix reagent (Promega) with a Bio-Rad real-time PCR machine according to the manufacturer's instructions. The relative quantification of gene expression was calculated as $2^{-\Delta \Delta \mathrm{Ct}}$. The expression levels of the target genes were normalized to the $\beta$-actin level in each sample. The primer sequences used are as follows: p53-forward, 5'-ACA GCG TGG TGG TAC CGT AT-3', reverse, 5'-GGA GCT GTT GCA CAT GTA CT-3'; Bcl-2-forward, 5'-GGG ATG CCT TTG TGG AAC TAT ATG-3', reverse, 5'-CAG CCA GGA GAA ATC AAA CAG A-3'; Bax-forward, 5'-AGA CAC CTG AGC TGA CCT TGG A-3', reverse, 5'-CGC TCA GCT TCT TGG TGG AT-3'; $\beta$-actin-forward, 5'-AGA GCT ATG AGC TGC CTG AC-3', reverse, 5'-AAT TGA ATG TAG TTT CAT GGA TG-3' ${ }^{17,18)}$

Statistical Analysis Data are expressed as the means \pm standard deviation and analyzed using SPSS 14.0 for Windows (SPSS, Chicago, IL, U.S.A.). Histopathological scores were analyzed with Kruskal-Wallis nonparametric ANOVA followed by Dunn's multiple comparison test. The remaining data were analyzed with one-way ANOVA, followed by a least square difference (LSD) multiple comparison test. Statistical significance was considered as $p<0.05$. 
A

\section{Serum creatinine}

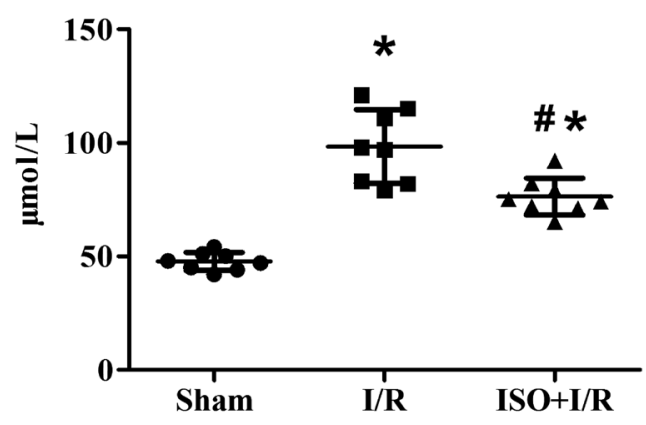

B

\section{Blood urea nitrogen}

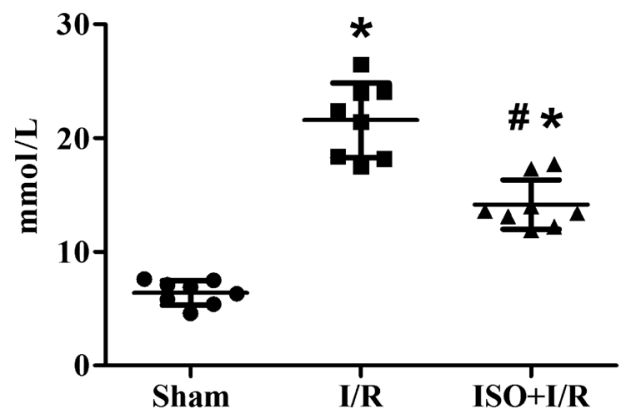

Fig. 1. Isoflurane Preconditioning Improved Renal Function after I/R Injury

$* p<0.01$ vs. sham group. $\# p<0.05$ vs. I/R group; $n=8$.

\section{RESULTS}

Isoflurane Preconditioning Improved Renal Function after I/R Injury Twenty-four hours after renal reperfusion, the I/R group developed significant renal dysfunction indicated by a rise in Scr $(98.25 \pm 16.17$ vs. 47.63 \pm 3.96$)$ and BUN $(21.56 \pm 3.28 v s .6 .40 \pm 1.07)$ levels. In contrast, isoflurane preconditioned rats had a significantly less drastic increase in

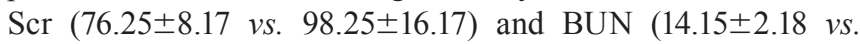
$21.56 \pm 3.28)$ levels. This suggests that isoflurane preconditioning exerts a renal protective role against I/R injury (Fig. 1).

Isoflurane Preconditioning Animals Showed Less Tu- bular Histopathological Damage Animals subjected to renal $\mathrm{I} / \mathrm{R}$ injury displayed extensive features of acute tubular damage, including cellular swelling, brush border loss, tubular dilatation, tubule cast formation, and inflammatory cell infiltration in the inner cortex and outer medullary regions. However, isoflurane preconditioned rats had less tubular epithelium and interstitium damage. The tubular damage scores were lower in the ISO $+\mathrm{I} / \mathrm{R}$ group than those in the $\mathrm{I} / \mathrm{R}$ group, although no significant difference was observed $(2.13 \pm 0.38 \mathrm{vs}$. $1.57 \pm 0.36, p=0.23 ; n=8)$. As expected, no tubular injury was found in sham controls (Fig. 2).

Preconditioning with Isoflurane Suppressed NF- $\kappa$ B Activation in Kidney To determine the level of NF- $\kappa \mathrm{B}$ activity after renal $\mathrm{I} / \mathrm{R}$ injury, phosphorylation of $\mathrm{IKK} \alpha / \beta$ and $\mathrm{I} \kappa \mathrm{B} \alpha$ was assessed for each group by Western blot analysis. The I/R group had significantly higher $\mathrm{p}-\mathrm{IKK} \alpha / \beta$ and $\mathrm{p}-\mathrm{I} \kappa \mathrm{B} \alpha$ levels and lower $\mathrm{I} \kappa \mathrm{B} \alpha$ than those in the sham group. These changes suggest increased NF- $\kappa \mathrm{B}$ activity. However, the ISO $+\mathrm{I} / \mathrm{R}$ group had less IKK $\alpha / \beta$ and $\mathrm{I} \kappa \mathrm{B} \alpha$ phosphorylation, and higher renal $\mathrm{I} \kappa \mathrm{B} \alpha$ protein expression than that in the I/R group (Fig. 3). Collectively, our data indicate that isoflurane is a negative regulator of NF- $\kappa \mathrm{B}$ activation following renal I/R injury.

Isoflurane Preconditioning Reduced the Levels of Inflammatory Cytokines We aimed to investigate whether isoflurane preconditioning affected the levels of inflammatory mediators in serum and kidney. As shown in Fig. 4, there was significantly more HMGB1, IL- $1 \beta$, and TNF- $\alpha$ in both serum and renal homogenate $24 \mathrm{~h}$ after renal reperfusion in the $\mathrm{I} / \mathrm{R}$ group compared with the sham group. However, the ISO $+\mathrm{I} / \mathrm{R}$ group had significantly lower inflammatory cytokine production than that in the $\mathrm{I} / \mathrm{R}$ group. This indicates that isoflurane preconditioning provides renoprotection against renal $I / R$ injury at least partly by attenuating renal and systemic inflammation.

Isoflurane Preconditioning Ameliorated Renal Tubular Apoptosis Induced by $\mathbf{I} / \mathbf{R}$ To evaluate the effect of isoflurane on renal apoptosis, TUNEL staining was performed on histological sections from sham, I/R, and $\mathrm{ISO}+\mathrm{I} / \mathrm{R}$ rats. Renal I/R rats had significantly more TUNEL-positive cells in tubules than those in the sham controls. Isoflurane preconditioning alleviated renal apoptosis induced by $\mathrm{I} / \mathrm{R}$, as evidenced by fewer TUNEL-positive cells in renal tubules of rats subjected to ISO $+\mathrm{I} / \mathrm{R}$ than those in controls $(2.93 \pm 0.81 \% v s$. 13.48土3.57\%) (Fig. 5).

Isoflurane Preconditioning Regulated Bcl-2/Bax Ratio
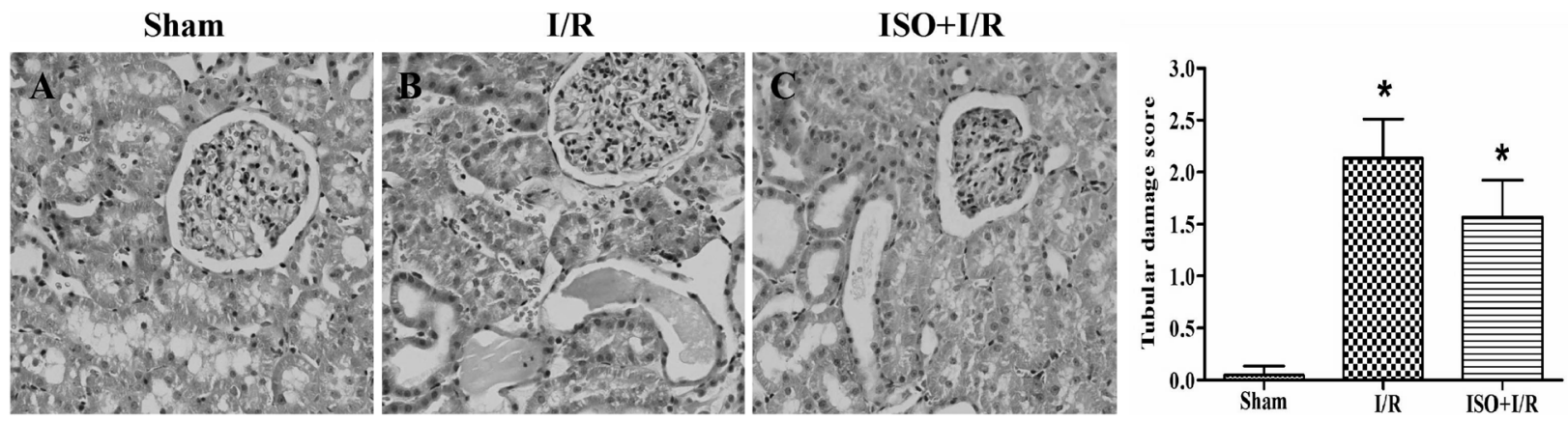

Fig. 2. Preconditioning with Isoflurane Slightly Ameliorated Tubular Damage Induced by I/R

Representative photomicrographs (hematoxylin and eosin staining, magnification $\times 200$ ) of the renal cortex from animals under various experimental conditions. (A) Renal tissue was normal in sham group (mean tubular damage score=0.15). (B) Significant cellular swelling, brush border loss, tubular dilatation, and tubule cast formation were present in $\mathrm{I} / \mathrm{R}$ group (mean tubular damage score=2.13). (C) Local brush border loss, tubular dilatation were observed in ISO+I/R group (mean tubular damage score=1.57). ${ }^{*} p<0.05$ vs. sham group, $n=8$. 
A

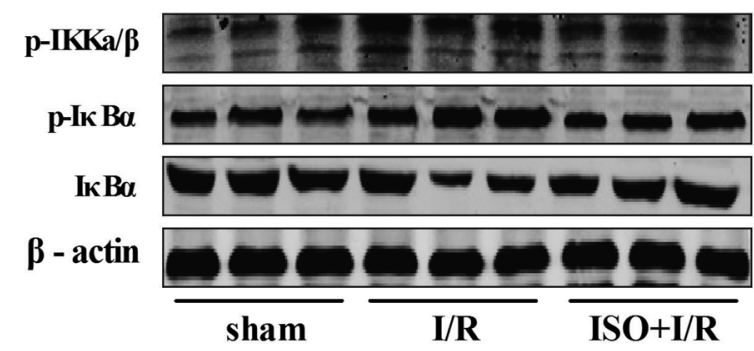

C

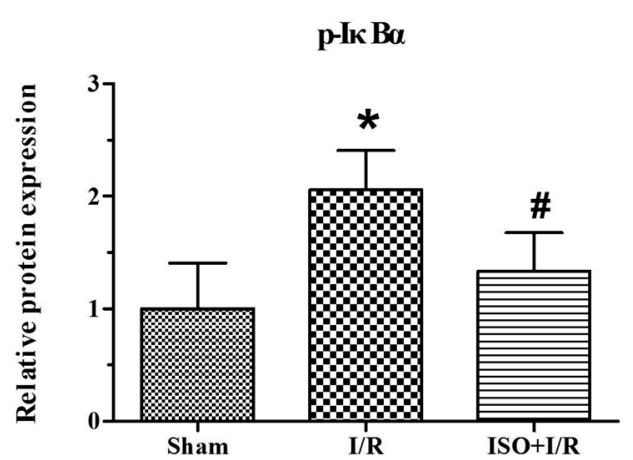

B

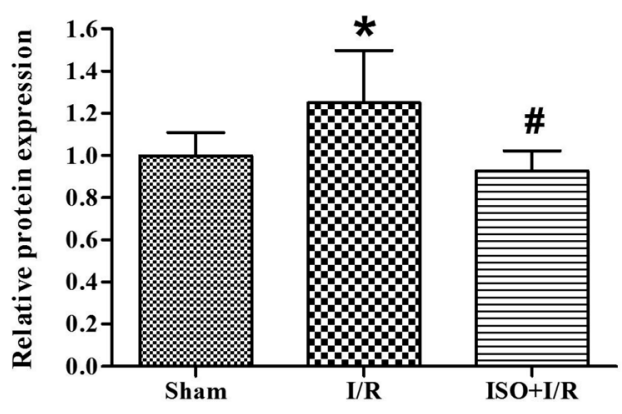

D

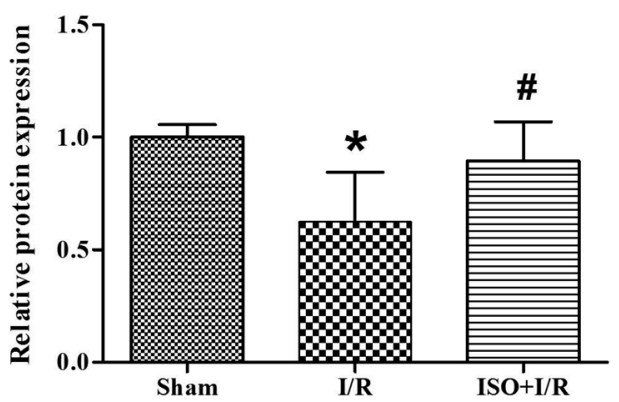

Fig. 3. Isoflurane Preconditioning Suppressed NF- $\kappa$ B Activation Caused by Renal I/R

Representative gel images of Western blot (A) and quantified graphs of $\mathrm{p}-\mathrm{IKK} \alpha / \beta$ (B), p-I $\kappa \mathrm{B} \alpha(\mathrm{C})$, and $\mathrm{I} \kappa \mathrm{B} \alpha(\mathrm{D}) .{ }^{*} p<0.05 v s$. sham group. \#p<0.05 $v s$. I/R group; $n=8$.

A

Serum HMGB1

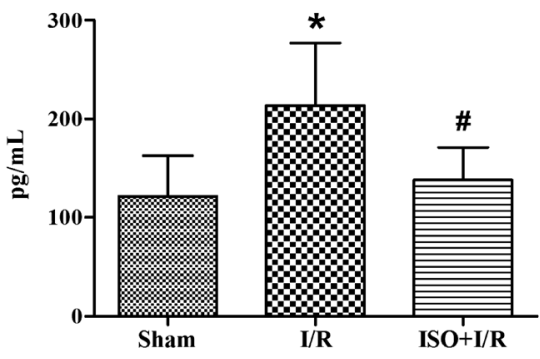

D

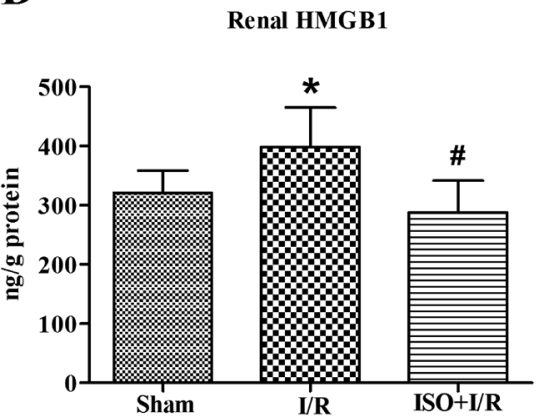

B

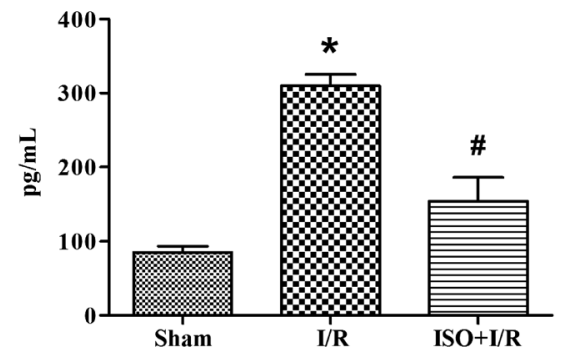

E

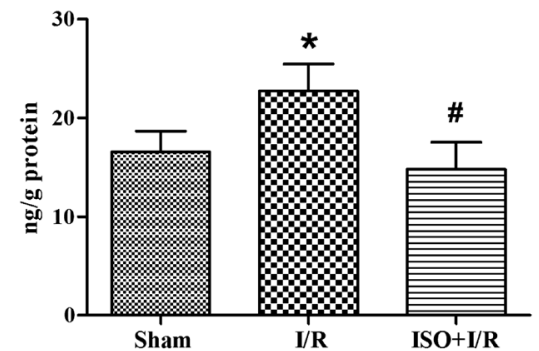

C

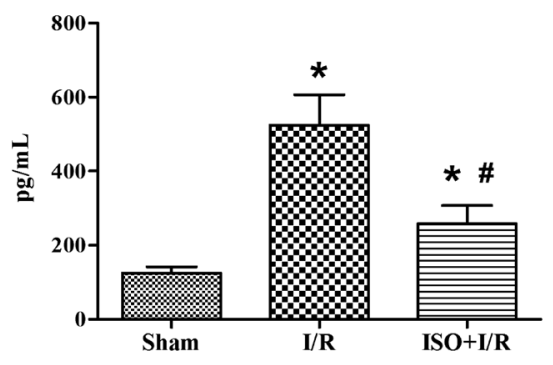

F

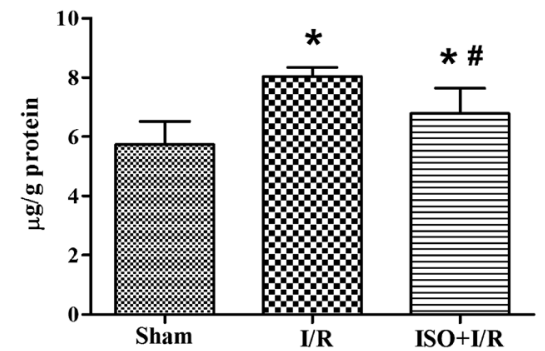

Fig. 4. Effects of Isoflurane Preconditioning on Serum and Renal Cytokine Production

Representative the levels of proinflammatory cytokines HMGB1, IL- $1 \beta$, and TNF- $\alpha$ in serum (A, B, C) and kidney homogenates (D, E, F). ${ }^{*} p<0.05 v s$. sham group. $\# p<0.05$ vs. I/R group; $n=8$.

and Cleaved Caspase-3 Expression after Renal I/R To further examine the mechanism underlying isoflurane protection against renal tubular apoptosis, mRNA and protein expression of $\mathrm{p} 53$, Bcl-2, Bax, and cleaved caspase- 3 was studied by quantitative PCR and Western blot analysis. Compared with sham controls, rats subjected to renal $\mathrm{I} / \mathrm{R}$ injury had a significantly lower Bcl-2/Bax ratio both in mRNA and protein levels. Isoflurane preconditioning rats had a markedly higher 


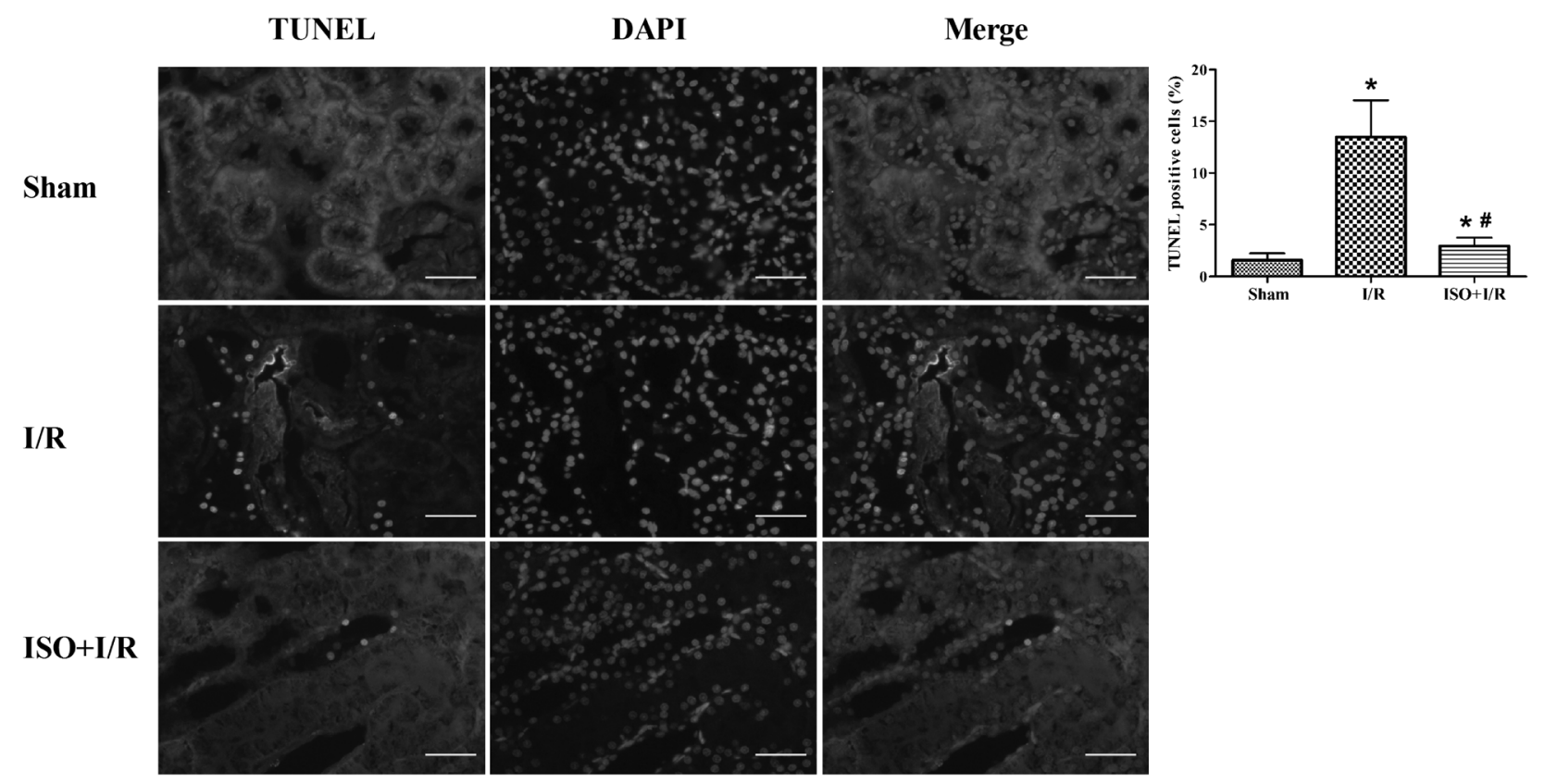

Fig. 5. Isoflurane Preconditioning Ameliorated Tubular Apoptosis Induced by Renal I/R

Representative images (magnification $\times 400$ ) of tubular TUNEL assay from rats subjected to sham-operation, renal $\mathrm{I} / \mathrm{R}$, and ISO+I/R. ${ }^{*} p<0.01 v s$. Sham group. $\# p<0.01$ vs. I/R group; $n=8$.

A

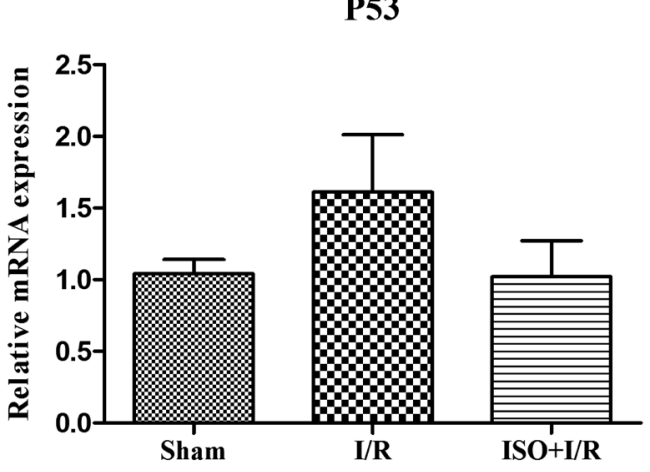

B

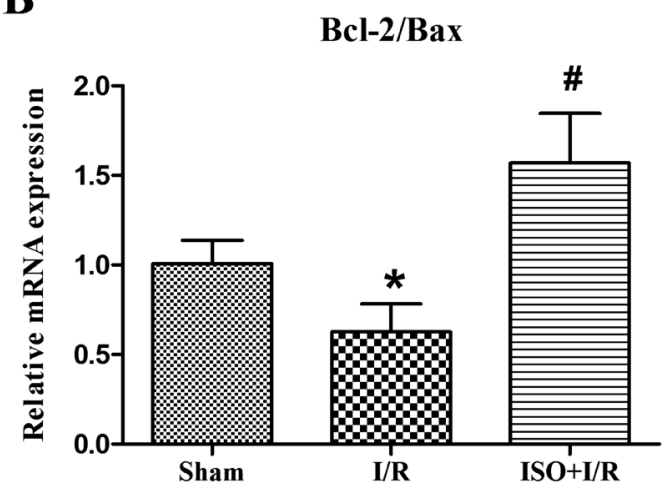

Fig. 6. Effects of Isoflurane Preconditioning on p53, Bcl-2, and Bax mRNA Expression after Renal I/R

Representative semi-quantitative graphs analyzed by quantitative PCR. $* p<0.05$ vs. sham group. $\# p<0.01$ vs. I/R group; $n=8$.

renal Bcl-2/Bax ratio after I/R (Figs. 6B, 7A, B). No significant difference was observed in p53 mRNA level among the three groups (Fig. 6A). In addition, it was noted that isoflurane preconditioned rats had markedly less renal caspase-3 frag-
A

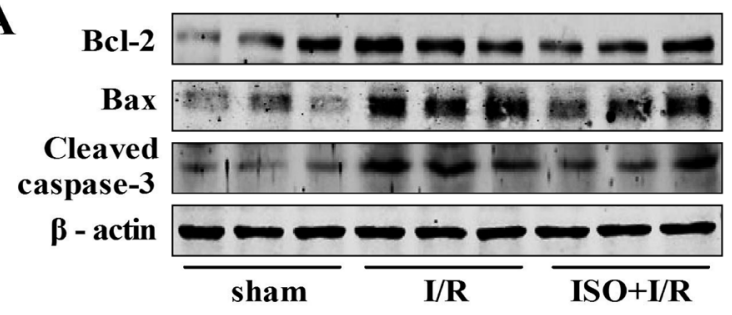

B

Bcl-2/Bax

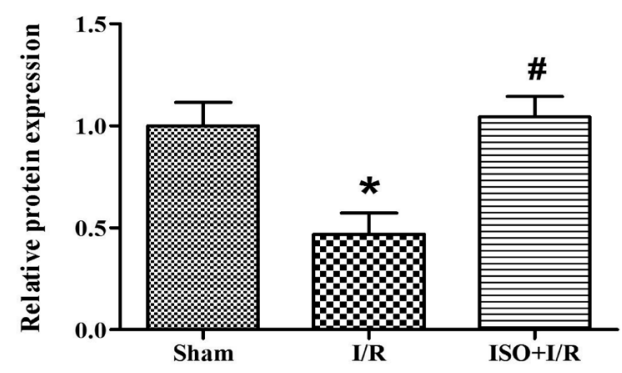

C

Cleaved caspase-3

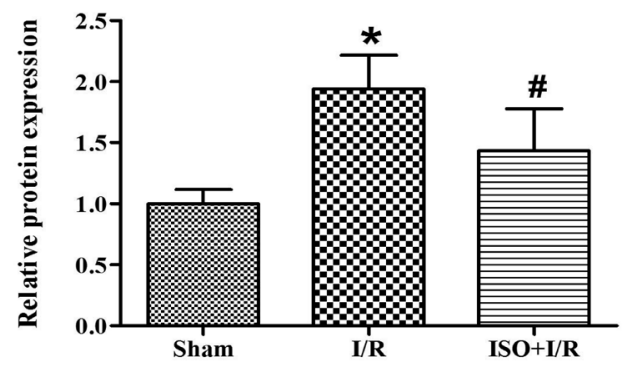

Fig. 7. Isoflurane Preconditioning Regulated Bcl-2/Bax Ratio and Cleaved Caspase-3 Protein Expression

Representative gel images of Western blot analysis of renal Bcl-2, Bax, and cleaved caspase-3 expression (A) as well as densitometric quantifications of band intensities relative to $\beta$-actin (B and C) from rats in each group. $* p<0.05 v s$. sham group. $\# p<0.01$ vs. I/R group; $n=8$. 
ments $24 \mathrm{~h}$ after reperfusion compared with those in the $\mathrm{I} / \mathrm{R}$ injury group (Fig. 7C).

\section{DISCUSSION}

In the present study, we demonstrated that isoflurane preconditioning can protect against renal $\mathrm{I} / \mathrm{R}$ injury in rats. Specifically, pretreatment with $1.5 \%$ isoflurane for $2 \mathrm{~h} \mathrm{im-}$ mediately before an $\mathrm{I} / \mathrm{R}$ challenge significantly attenuated the increase in Scr and BUN. In addition, isoflurane significantly suppressed NF- $\kappa \mathrm{B}$ activation and decreased the expression of inflammatory cytokines. We also confirmed that isoflurane preconditioning attenuated tubular apoptosis and regulated the imbalance of Bcl-2/Bax expressions and caspase-3 activation caused by renal $\mathrm{I} / \mathrm{R}$ injury.

Isoflurane is capable of inducing preconditioning and postconditioning effects in renal I/R injury, which appears to be independent of the effects on systemic blood pressure or renal blood flow. ${ }^{11,12,19)}$ Identifying the mechanisms by which isoflurane mediates renoprotection may be clinically significant during the perioperative period. Here, we reported that the regulation of isoflurane preconditioning on NF- $\kappa \mathrm{B}$-mediated inflammation and dysfunction of the p53-Bax-caspase-3 apoptotic pathway may be the underlying mechanisms involved in renoprotection.

The activation of NF- $\kappa \mathrm{B}$ is dependent on the dissociation from its inhibitory protein $\mathrm{I} \kappa \mathrm{B}$ via the phosphorylation of IKK $\alpha / \beta^{13)}$. In the present study, we observed that the canonical NF- $\kappa \mathrm{B}$ signaling pathway was activated, as evidenced by marked upregulation of $\mathrm{p}-\mathrm{IKK} \alpha / \beta$ and $\mathrm{p}-\mathrm{I} \kappa \mathrm{B} \alpha$, and degradation of $\mathrm{I} \kappa \mathrm{B} \alpha$ following $\mathrm{I} / \mathrm{R}$ challenge. Isoflurane preconditioning suppressed NF- $\kappa \mathrm{B}$ activation, which occurred in parallel with reductions in renal injury from $\mathrm{I} / \mathrm{R}$ both functionally and histologically. Our results were consistent with a previous study in which inhibition targeting IKK $\alpha / \beta$ using small interfering RNA provided renal protection in a rat model of ischemic AKI. ${ }^{20)}$

HMGB1 is another nuclear factor known to participate in DNA replication and transcriptional activation. ${ }^{21}$ In addition to its nuclear roles, HMGB1 can be released extracellularly from necrotic or damaged cells and function as an important mediator to trigger local and systemic inflammation. ${ }^{22,23)}$ Reportedly, endogenous HMGB1 expression was upregulated following renal $\mathrm{I} / \mathrm{R}$ injury, particularly in tubular epithelial cells. $^{24)}$ HMGB1 initiates a signaling cascade leading to activation of NF- $\kappa \mathrm{B}$ and upregulation of downstream proinflammatory genes in a mouse model of renal $\mathrm{I} / \mathrm{R}$ injury, and administration of a neutralizing antibody to HMGB1 provided significant renoprotection. ${ }^{25,26)}$ In agreement with these results, we found that isoflurane preconditioning not only reduced the elevated circulating and renal HMGB1 levels, but also suppressed NF- $\kappa \mathrm{B}$, downstream IL- $1 \beta$, and TNF- $\alpha$ expression $24 \mathrm{~h}$ after reperfusion. Therefore, renoprotection may be mediated by inhibiting NF- $\kappa \mathrm{B}$ activation and the production of the proinflammatory cytokines. Previous studies have reported that HMGB1, IL- $1 \beta$, and TNF- $\alpha$ can act as both the activators and target genes of NF- $\kappa \mathrm{B}$ during the inflammatory response. ${ }^{27-29)}$ However, their precise interactions in renal $\mathrm{I} / \mathrm{R}$ injury remain unclear. We hypothesize that there is not a simple cause-effect relationship between $\mathrm{NF}-\kappa \mathrm{B}$ activation and excessive cytokine release in the inflammatory cascade induced by renal I/ $R$ in- jury.

Apoptosis is another pathological process involved in renal I/R injury. There are two major apoptosis signaling pathways, namely the intrinsic mitochondrial pathway and the extrinsic death receptor pathway. ${ }^{30)}$ In the mitochondrial pathway, the relative levels of Bax and Bcl-2 have been proposed to play a role in cell survival after ischemia and reperfusion. ${ }^{31,32)}$ Consistent with these studies, our results indicate that $30 \mathrm{~min}$ of renal ischemia and $24 \mathrm{~h}$ of reperfusion caused a decrease in the ratio of $\mathrm{Bcl}-2 / \mathrm{Bax}$ at both the mRNA and protein levels. Moreover, we have found that caspase-3, an executioner caspase that represents a point of convergence in the intrinsic and extrinsic apoptotic pathways, was also activated following I/R. Isoflurane preconditioning prevented these changes, leading to an increased $\mathrm{Bcl}-2 / \mathrm{Bax}$ ratio and reduced cleaved caspase- 3 protein expression, thus inhibiting the increase of TUNELpositive cells in tubules. Previous studies have revealed that isoflurane attenuate renal $\mathrm{I} / \mathrm{R}$ injury by modulating leukocyte influx, blunting the protein kinases JNK and ERK activation, upregulating HIF- $1 \alpha$, and activating the SK/S1P signaling pathway. ${ }^{11,12,15,19)}$ Their detailed interaction with the anti-inflammatory and anti-apoptotic actions of isoflurane proposed in our study still needs further investigation.

Our investigation has several limitations. First, we tested only a single concentration (1.5\%) for a single duration ( $2 \mathrm{~h}$ ) of isoflurane preconditioning. Therefore, dose-dependent protection cannot be determined from this study. However, the dose we used is within the clinical range. Second, our study emphasized the role of isoflurane preconditioning in renal $\mathrm{I} / \mathrm{R}$ induced cell apoptosis and inflammation pathways. Inflammation after renal $\mathrm{I} / \mathrm{R}$ injury is a major contributor to renal cell death. ${ }^{15)}$ Nevertheless, we did not investigate the crosstalk between NF- $\kappa$ B-mediated inflammation and the p53-Bax-caspase- 3 apoptotic pathway in this complex process. Therefore, further research on this issue is warranted.

In conclusion, we have demonstrated that isoflurane preconditioning at a clinically relevant concentration reduces the degree of renal $\mathrm{I} / \mathrm{R}$ injury. Inhibition of inflammation and the mitochondrial apoptotic pathway might be involved in the renoprotective actions.

Acknowledgments This work was supported by the National Natural Science Foundation of China (81371205, 81070213) and the Doctoral Fund of the Ministry of Education of China (20110001110008).

\section{REFERENCES}

1) Gueler F, Gwinner W, Schwarz A, Haller H. Long-term effects of acute ischemia and reperfusion injury. Kidney Int., 66, 523-527 (2004).

2) Rabadi MM, Ghaly T, Goligorksy MS, Ratliff BB. HMGB1 in renal ischemic injury. Am. J. Physiol. Renal Physiol., 303, F873-F885 (2012).

3) Yang JR, Yao FH, Zhang JG, Ji ZY, Li KL, Zhan J, Tong YN, Lin LR, He YN. Ischemia-reperfusion induces renal tubule pyroptosis via the CHOP-caspase-11 pathway. Am. J. Physiol. Renal Physiol., 306, F75-F84 (2014).

4) Kelly KJ, Sutton TA, Weathered N, Ray N, Caldwell EJ, Plotkin Z, Dagher PC. Minocycline inhibits apoptosis and inflammation in a rat model of ischemic renal injury. Am. J. Physiol. Renal Physiol., 287, F760-F766 (2004). 
5) Jin X, Chen J, Hu Z, Chan L, Wang Y. Genetic deficiency of adiponectin protects against acute kidney injury. Kidney Int., 83, 604-614 (2013).

6) Havasi A, Borkan SC. Apoptosis and acute kidney injury. Kidney Int., 80, 29-40 (2011).

7) Kurokawa M, Kornbluth S. Caspases and kinases in a death grip. Cell, 138, 838-854 (2009).

8) Jamnicki-Abegg M, Weihrauch D, Pagel PS, Kersten JR, Bosnjak ZJ, Warltier DC, Bienengraeber MW. Isoflurane inhibits cardiac myocyte apoptosis during oxidative and inflammatory stress by activating Akt and enhancing Bcl-2 expression. Anesthesiology, 103, 1006-1014 (2005).

9) Schmidt R, Tritschler E, Hoetzel A, Loop T, Humar M, Halverscheid L, Geiger KK, Pannen BH. Heme oxygenase-1 induction by the clinically used anesthetic isoflurane protects rat livers from ischemia/reperfusion injury. Ann. Surg., 245, 931-942 (2007).

10) Zhou Y, Lekic T, Fathali N, Ostrowski RP, Martin RD, Tang J, Zhang JH. Isoflurane posttreatment reduces neonatal hypoxic-ischemic brain injury in rats by the sphingosine-1-phosphate/phosphatidylinositol-3-kinase/Akt pathway. Stroke, 41, 1521-1527 (2010).

11) Zhang L, Huang H, Cheng J, Liu J, Zhao HL, Vizcaychipi MP, Ma DQ. Pre-treatment with isoflurane ameliorates renal ischemicreperfusion injury in mice. Life Sci., 88, 1102-1107 (2011).

12) Hashiguchi $\mathrm{H}$, Morooka $\mathrm{H}$, Miyoshi $\mathrm{H}$, Matsumoto $M$, Koji $\mathrm{T}$, Sumikawa K. Isoflurane protects renal function against ischemia and reperfusion through inhibition of protein kinases, JNK and ERK. Anesth. Analg., 101, 1584-1589 (2005).

13) Li ZQ, Rong XY, Liu YJ, Ni C, Tian XS, Mo N, Chui DH, Guo $X Y$. Activation of the canonical nuclear factor-kappaB pathway is involved in isoflurane-induced hippocampal interleukin-lbeta elevation and the resultant cognitive deficits in aged rats. Biochem. Biophys. Res. Commun., 438, 628-634 (2013)

14) Liu Y, Ni C, Tang Y, Tian X, Zhou Y, Qian M, Li ZQ, Chui D, Guo $\mathrm{X}$. Melatonin attenuates isoflurane-induced acute memory impairments in aged rats. Basic Clin. Pharmacol. Toxicol., 113, 215-220 (2013).

15) Lee HT, Kim M, Kim M, Kim N, Billings FT 4th, D'Agati VD, Emala CW Sr. Isoflurane protects against renal ischemia and reperfusion injury and modulates leukocyte infiltration in mice. Am. $J$. Physiol. Renal Physiol., 293, F713-F722 (2007).

16) Jablonski P, Howden BO, Rae DA, Birrell CS, Marshall VC, Tange J. An experimental model for assessment of renal recovery from warm ischemia. Transplantation, 35, 198-204 (1983).

17) Molitoris BA, Dagher PC, Sandoval RM, Campos SB, Ashush H, Fridman E, Brafman A, Faerman A, Atkinson SJ, Thompson JD, Kalinski H, Skaliter R, Erlich S, Feinstein E. siRNA targeted to p53 attenuates ischemic and cisplatin-induced acute kidney injury. $J$. Am. Soc. Nephrol., 20, 1754-1764 (2009).

18) Gui D, Guo Y, Wang F, Liu W, Chen J, Chen Y, Huang J, Wang N. Astragaloside IV, a novel antioxidant, prevents glucose-induced podocyte apoptosis in vitro and in vivo. PLoS ONE, 7, e39824 (2012).

19) $\overline{\operatorname{Kim}} \mathrm{M}$, Kim M, Kim N, D’Agati VD, Emala CW Sr, Lee HT. Isoflurane mediates protection from renal ischemia-reperfusion injury via sphingosine kinase and sphingosine-1-phosphate-dependent pathways. Am. J. Physiol. Renal Physiol., 293, F1827-F1835 (2007).

20) Wan X, Fan L, Hu B, Yang J, Li X, Chen X, Cao CC. Small interfering RNA targeting IKKbeta prevents renal ischemia-reperfusion injury in rats. Am. J. Physiol. Renal Physiol., 300, F857-F863 (2011).

21) Bianchi ME, Beltrame M, Paonessa G. Specific recognition of cruciform DNA by nuclear protein HMG1. Science, 243, 1056-1059 (1989).

22) Yang H, Wang H, Czura CJ, Tracey KJ. The cytokine activity of HMGB1. J. Leukoc. Biol., 78, 1-8 (2005).

23) Scaffidi P, Misteli T, Bianchi ME. Release of chromatin protein HMGB1 by necrotic cells triggers inflammation. Nature, 418, 191-195 (2002).

24) Wu H, Chen G, Wyburn KR, Yin J, Bertolino P, Eris JM, Alexander SI, Sharland AF, Chadban SJ. TLR4 activation mediates kidney ischemia/reperfusion injury. J. Clin. Invest., 117, 2847-2859 (2007).

25) Wu H, Steenstra R, de Boer EC, Zhao CY, Ma J, van der Stelt JM, Chadban SJ. Preconditioning with recombinant high-mobility group box 1 protein protects the kidney against ischemia-reperfusion injury in mice. Kidney Int., 85, 824-832 (2014).

26) Wu H, Ma J, Wang P, Corpuz TM, Panchapakesan U, Wyburn KR, Chadban SJ. HMGB1 contributes to kidney ischemia reperfusion injury. J. Am. Soc. Nephrol., 21, 1878-1890 (2010).

27) Pahl HL. Activators and target genes of Rel/NF-kappaB transcription factors. Oncogene, 18, 6853-6866 (1999).

28) Yang Y, Wang J, Yang Q, Wu SS, Yang ZG, Zhu HH, Zheng M, Liu WX, Wu W, He JL, Chen Z. Shikonin inhibits the lipopolysaccharide-induced release of HMGB1 in RAW264.7 cells via IFN and NF-kappaB signaling pathways. Int. Immunopharmacol., 19, 81-87 (2014)

29) Mudaliar H, Pollock C, Komala MG, Chadban S, Wu H, Panchapakesan U. The role of Toll-like receptor proteins (TLR) 2 and 4 in mediating inflammation in proximal tubules. Am. J. Physiol. Renal Physiol., 305, F143-F154 (2013).

30) Haupt S, Berger M, Goldberg Z, Haupt Y. Apoptosis-the p53 network. J. Cell Sci., 116, 4077-4085 (2003).

31) Zhao ZQ, Nakamura M, Wang NP, Velez DA, Hewan-Lowe KO, Guyton RA, Vinten-Johansen J. Dynamic progression of contractile and endothelial dysfunction and infarct extension in the late phase of reperfusion. J. Surg. Res., 94, 133-144 (2000).

32) Zhao ZQ, Budde JM, Morris C, Wang NP, Velez DA, Muraki S, Guyton RA, Vinten-Johansen J. Adenosine attenuates reperfusioninduced apoptotic cell death by modulating expression of Bcl-2 and Bax proteins. J. Mol. Cell. Cardiol., 33, 57-68 (2001). 